\title{
Optimizing Ship Berthing
}

\author{
Gerald G. Brown, Siriphong Lawphongpanich, and Katie Podolak Thurman \\ Naval Postgraduate School, Monterey, California 93943
}

\author{
All places that the eve of heaven visits \\ are to a wise man ports and happy havens. Shakespeare. Richard II
}

\begin{abstract}
Ship berthing plans reserve a location for inbound U.S. Navy surface vessels prior to their port entrance, or reassign ships once in port to allow them to complete, in a timely manner, reprovisioning, repair, maintenance, training. and certification tests prior to redeploying for future operational commitments. Each ship requires different services when in port. such as shore power. crane. ordnance. and fuel. Unfortunately, not all services are offered at all piers, and berth shifting is disruptive and expensive: A port operations scheduler strives to reduce unnecessary berth shifts. We present an optimization model for berth planning and demonstrate it for Norfolk Naval Station, which exhibits all the richness of berthing problems the Navy faces. $194+$ John Wiley \& Sons. Inc.
\end{abstract}

\section{INTRODUCTION}

While most ships' missions are executed at sea, their in-port time is essential to maintain a high degree of material readiness and crew morale: Efficient ship berthing is important. A ship herthing plan assigns surface vessels a berth prior to entering port or reassigns ships once in port "to accomplish a progression of maintenance training and certification events which build readiness for future operational commitments" [15]. These events include combat systems maintenance, tests. and training. amphibious in-port deck evolutions, and other in-port functions relevant to an individual ship class [7].

Prior to the port arrival of a commissioned naval ship or fleet auxiliary ship, the commanding officer sends a message to the appropriate naval authority stating the logistic requirements (LOGREQ) of his ship during the period in port [11]. This LOGREQ specifies any requests a ship may have due to upcoming inspections, operational commitments, maintenance requirements, or any other consideration the commanding officer identifies.

Port operation ship berthing schedulers review logistic requirements, quarterly employment schedules, and squadron requests for all home-based and visiting ships. and make berth assignments based on fleet requirements and port capabilities. Factors considered in berth assignments include pier service requirements, deployment status, special operational tests, ship and berth characteristics, as well as crane requirements for onor off-loading supplies. These considerations must be taken into account since each berth is unique in its capabilities: Each berth may offer differing shore power and crane services. depth and length of slip, fuel or ammunition loading capability and fendering system [12].

An ideal ship berthing plan which minimizes port loading problems would require that all possible berths for each vessel be examined and "the one which best promotes fleet readiness while minimizing contlict between the inport goals would be chosen " [15]. As a practical matter, this is impossible for a human scheduler to do. There are simply

Naral Research Logistics, Vol. 41. pp. 1-15 (1994)

Copyright 1994 by John Wiley \& Sons. Inc.

CCC (1894-(1)69X/94/(010)001-15 
too many details to consider over time, and comparison of the goodness of alternate plans is problematic.

In order to assign ships to a sequence of berths that offer required services while minimizing the number of berth shifts required, we formalize and quantify berthing rules and ship priorities and develop appropriate measures of effectiveness. A computerized optimization model is developed and tested to assist the schedulers in the creation of a berthing plan which minimizes port loading conflicts. thus promoting fleet readiness through berthing stability.

\section{NAVAL STATION NORFOLK}

We study the Navy's largest base: Naval Station Norfolk. Virginia (NAVSTANORVA), a base which exhibits all features seen at other bases.

The mission of Naval Station Norfolk is

. . . 10 provide, as appropriate. logistic support for the Operating Forces of the Navy. . . The Port Services Ofticer (atso known as the Port Operations Officer) is responsible . . . for . . . the alssignment of berths and anchorages: the use of piers, landing sites. pilots: coordination of logistic requests lor supplies, fuel. medical services. communications, hazardous material handling and other services... . [s].

The Norfolk Naval Station consists of 15 piers which exhibit different physical characteristics and services. Figure 1 depicts 14 of these piers. Typically, the average number

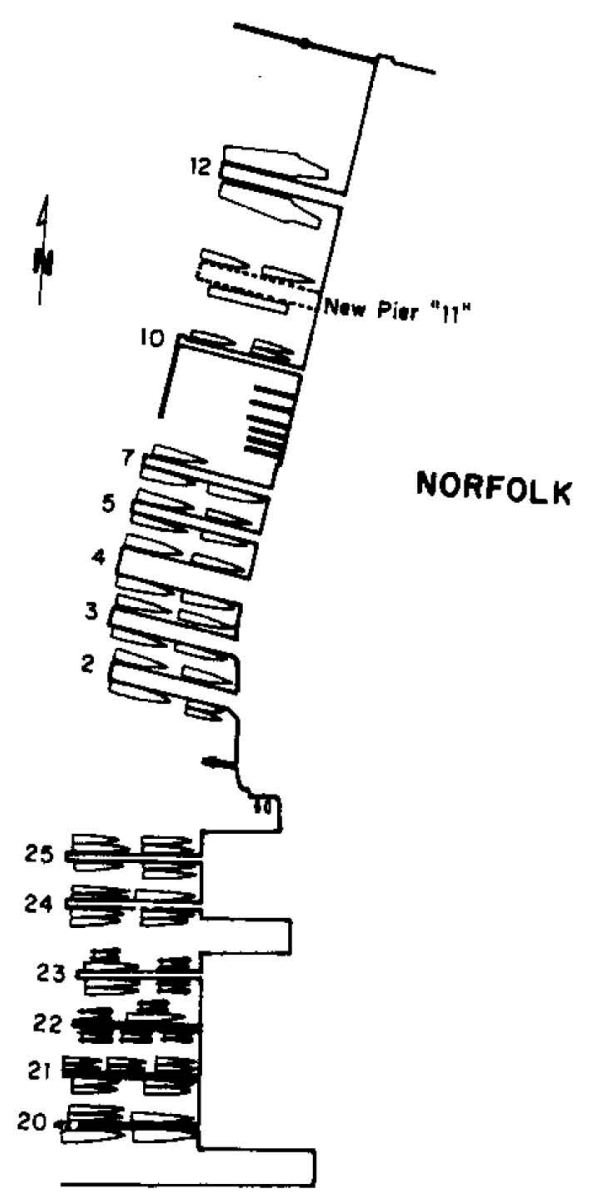

Figure 1. Naval Station Norfolk piers. 
of ships in port is 50) with the highest port load at 74 during the Christmas holiday. These vessels usually rely on shore power rather than on their own power. Shore power and other facilities permit ships to operate and test combat systems and other mission capabilities while in port [7]. The increasing number of ships homeported at Norfolk (presently 118), along with unique requirements by ships and lengthy pier maintenance projects. combine to make pier scheduling an extremely difficult task requiring complex planning [6].

The Naval Station Norfolk ship berthing plans are manually prepared by the schedulers with the aid of pen and paper and a wall-size mock-up of the pier layout with scale-size ship silhouettes. Once informed of which ships are scheduled to be in port for the next week, the scheduler first determines which berths can physically accommodate each ship.

The berth scheduling rationale is based on the following primary criteria:

- The ship is length must be less than the length of the pier.

- The pier-side depth must be five feet greater than the ships draft to allow for tidal change as well as propeller wash and engincering plant requirements.

- The ship s beim plus fender system must extend less than the distance between the berth and the next closest pier or berthed ship plas room to allow a ship to matneuver.

- The berth should provide at least the minimum required number of shore power cables $[7]$.

After the physically feasible berths are identified for each ship, the scheduler then considers a secondary set of guidelines specific to Norfolk, shown in Appendix A. Every port has an analogous set of local berthing criteria.

At this point, scheduling becomes difficult. The scheduler assigns each ship to a feasible berth and tries to maximize the proportion of requested services and minimize the number of berth shifts required to accommodate these requests over time. This berth plan is the initial input to a key planning event, the berthing conference.

Once a week, a berthing conference is held at port operations and attended by representatives from squadrons, groups, type commanders, Military Sealift Command, Norfolk Supply C'enter, Public Works Center (PWC, utilities, and crane scheduler), Readiness Support Group and Port Operations (scheduler, chief pilot, ordnance officer, dockmaster, and policy maker). The squadrons all represent their ships requests for docking and undocking times, as well as for particular berth assignments. PWC advertises feasible pier utility services. The pilot assigns move times for ships constrained by tide. Compromises are worked out and the Port Operations Officer makes final decisions [12].

The final berthing plan resulting from the berthing conference is used as the start of the following week's schedule. Coordination among all these participants is vital. Changes in the announced plan are inevitable-the schedule often changes hourly. The sheer frequency of revisions makes a strong case for the use of a computerized, optimizing berthing plan. The consequence of oversights is delay, and delays cost time and money.

\section{A SHIP BERTHING MODEL}

The goal is to cruate an optimal berthing plan. at a daily level of detail, for all ships scheduled to be in port during the prospective planning horizon (say, a week).

The situation calls for at set of discrete ship-to-berth assignments. with limitations on feasible assignments. These limitations (on length. draft. power cables, and so forth) are easily expressed as linear functions of ship-to-berth assignment variables. This suggests a linear integer program. 


\section{Model Formulation}

\section{Indices}

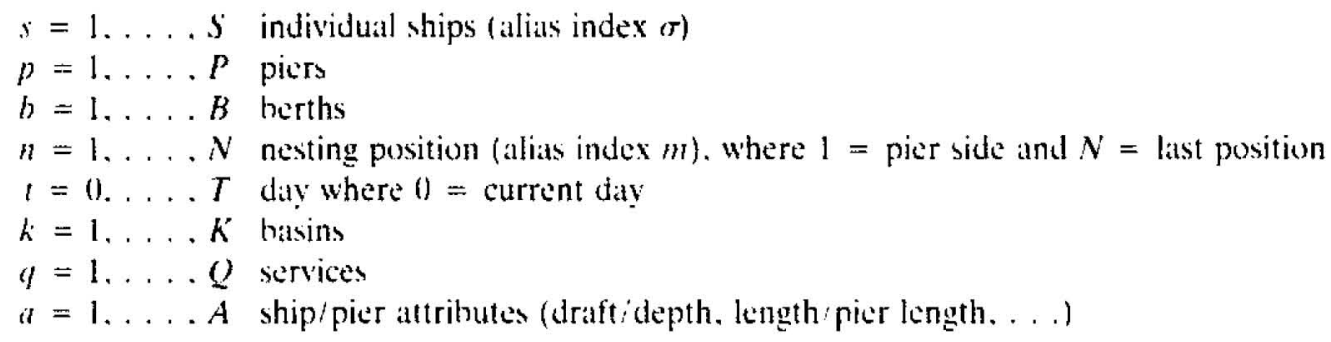

$\sigma$ and $m$ are simply alternate indices for referring to the ships and nesting positions. respectively. Such alias indexing is required when describing the constraints below. The indices $p, b, n$, and $k$ refer to nautical terms illustrated in Figure 2.

In general, ships can be berthed on both sides of a pier and index $p$ distinguishes between each side. In Figure 2, $p$ can represent 12N, 12S. 11N, 11S. and 10N. Pier $10 \mathrm{~S}$ is for small ships and it is not included in our problem. A pier is typically long enough for two ships to berth pier side, in which case $B=2$ indicates two berthing positions. At a given berthing position of a pier, up to three ships can usually be nested alongside one another (see berth 2 of pier $11 \mathrm{~N}$ in Figure 2), implying that $N=3$ in the above definition of indices. Finally. a basin refers to a space surrounded by two piers as indexed by $p$. Figure 2 displays two basins. One includes $11 \mathrm{~N}$ and $12 \mathrm{~S}$ and the other includes $10 \mathrm{~N}$ and $11 \mathrm{~S}$.

\section{Given and Derived Data}

$\Omega(s) \quad$ indices of ships which are shorter than ship $s$

$\Omega(s) \quad$ indices of ships which are shorter than or cyual in length to ship ,

DAY 5
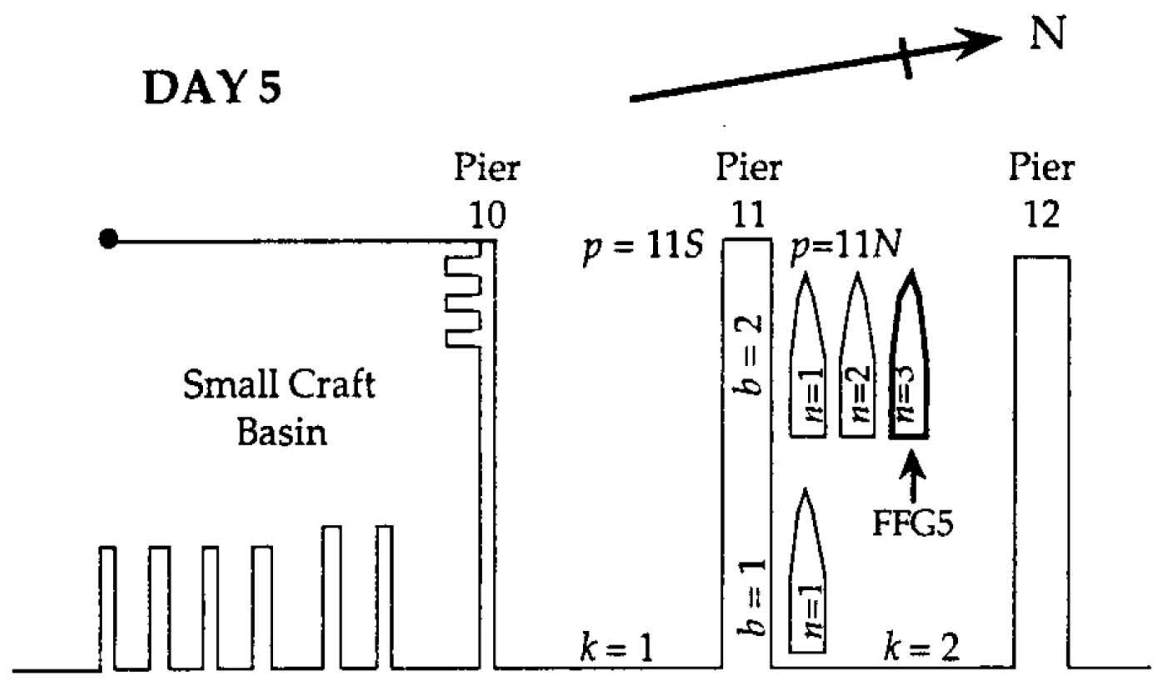

On day $t=5$, ship FFG5 is berthed at pier $p=11 N$, berth $b=2$, nesting position $n=3$.

Figure 2. Ship berthing indices for basin $h \cdots 1$ and 2 . 


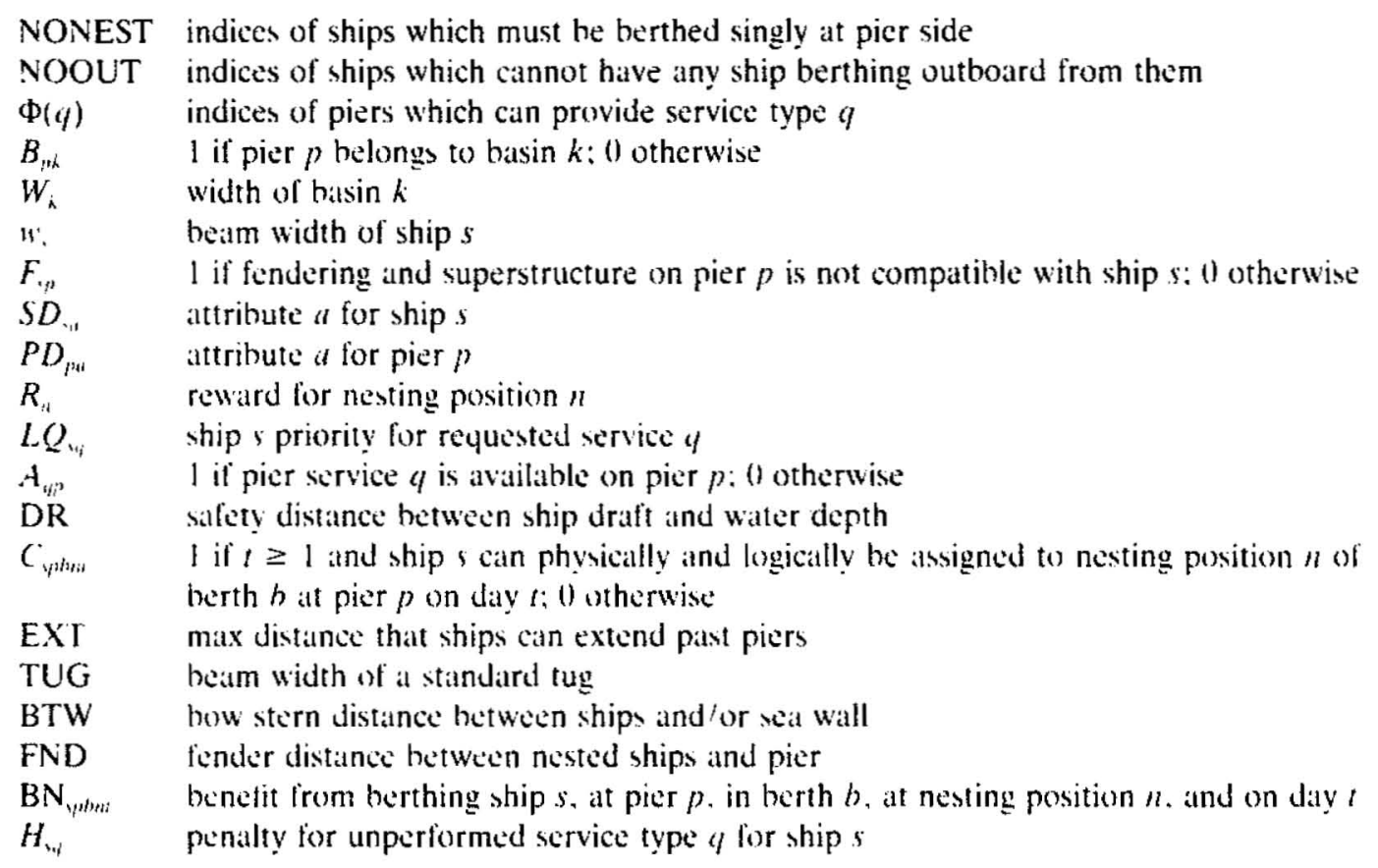

Among the above collection of data, $C_{s p h n t}$ determines whether a ship can be assigned to (or is compatible with) one of the specified berths at a pier. Such an assignment is possible, i.e., $C_{v p h t}=1$, as long as all of the following primary berthing conditions (1)(5) are satisfied. If these primary berthing criteria are violated for every pier associated with each specified berth, the ship cannot berth and the problem is deemed infeasible.

$$
\begin{gathered}
S D_{\text {s.drift }} \leq P D_{p, \text { depth }}-\mathrm{DR}, \\
S D_{\text {, length }} \leq P D_{p \text {.kng̣th. }} . \\
S D_{\text {, arrive }} \leq t, \\
S D_{\text {, depart }} \geq t, \\
F_{s p}=0 .
\end{gathered}
$$

Condition (1) ensures the pier depth is deep enough for the ship's draft plus safety distance. Condition (2) berths a ship only if its length does not extend past the pier. For a ship to be considered compatible, it must be scheduled to be in port during the day considered as ensured by conditions (3) and (4). Condition (5) does not allow a ship to be assigned a berth where it would have a fendering or superstructure interference.

In order to help the human scheduler, rather than (foolishly) try to replace him. extensive capability should be provided to allow manual assignment of a ship to a specitied berth, subset of piers berths, or nesting position. These coercions are simulated in the prototypic implementation via input of the compatibility data, $C_{s p h m}$. derived above. This allows the scheduler to restrict any or all permitted indices for a ship. i.e.. a specified berth. group of berths piers. and or nesting position for a specified ship during any or all days the vessel is scheduled to be in port. When the user identifies specific requests. all other $C_{, p m}$ are automatically set to zero, thus ensuring the ship will be berthed only as specified by the scheduler. 
The objective is the "goodness" of any given feasible berthing plan. The problem is greatly simplified if this benefit can be expressed as an additive, separable linear function of individual ship-to-berth assignments. To provide such an objective function, individual ship service requests are prioritized among and between ship classes: larger ships such as aircraft carriers are authorized higher priorities for services than destroyers or frigates. The benefit is expressed as a function based on this ship priority for services, pending inspections, deployments, whether the pier offers any or all of the requested services and how far into the future the decision will be committed.

Recognizing the time value of information and uncertainty, an exponential function discounts the preference awarded to a ship desiring a berth in the future versus a ship requesting it today.

$B N_{, m m}$ benefit from berthing ship s. at pier $p$. in berth $b$, at nesting position $n$, on day $t$; derived only if $C_{v_{i}, t_{\text {rit }}}=1$, and detined as follows:

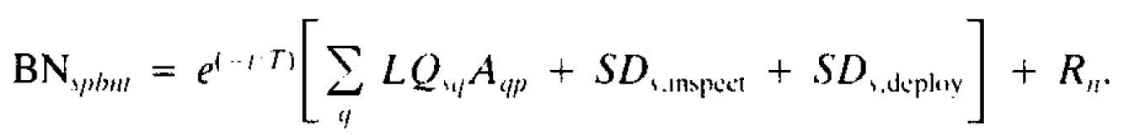

The benefit of a potential assignment is thus calculated by summing, term by term, the pairwise products of the weighted ship requests $(L Q)$ with the vector $(A)$ which identifies services available at each pier. This is an indication of how well each berth satisfies a ship's needs. The inspection and deployment (SD) factors are then added to the weighted ship requests; this allows a ship with an upcoming inspection or deployment to be ranked higher than other ships of the same type. The updated weight is multiplied by an exponential term to give greater consideration to ships requesting services today than ships scheduled to be in port in the future. Lastly. a reward $(R)$ based on nesting position is added to yield the final benefit for assigning the ship to a specific berth. This final nesting position reward encourages the model to berth ships pier side.

\section{Variables}

$X_{\text {, ibu }}$ A binary variable specifying if ship $s$ is to be berthed at pier $p$, in berth $b$, at nesting position $n$. on day $t$. In the implementation, the variable, $X_{, y m}$ is included in the model only when $C_{y m m}=1$. To take into account the fact that the berthing of ships is an ongoing process. $1=0$ indicates a ship's current position.

$L_{\text {, } p \text { inu }}$ indicates if ship $s$ shifted to pier $p$, in berth $b$. at nesting position $n$. on day $t$. This variable is generated only if the ship was berthed on day $t-\mathrm{I}$.

$l$ indicates if requested service type $q$ is not performed lor ship s.

Technically, variable $Z_{p p h m}$ can have values of 0 or 1 to indicate any berth shifting of ships already in port. To account for berth shifting, $Z_{\mathrm{v} p h m}$ is simply defined as a difference between $X_{\text {spm }}$ and $X_{y p h m t-11}$, both of which are binary. This naturally induces the integrality restriction when combined with the objective function introduced below. Thus, $Z_{\text {iphm }}$ is stated and implemented as a continuous variable between 0 and 1 . Similarly, $U_{1, y}$ is technically a binary variable. However, it is stated as a continuous variable hecause the objective function and the constraints naturally restrict the value of $U_{y /}$ to 0 or 1 .

To simplify the presentation, the variables $X_{\text {sphm }}$ and $Z_{s p h m}$ and the parameter $\mathrm{BN}_{\text {, } h m}$ are present in the following formulation only if $C_{s p h m}=1$. In addition, all constraints 
are defined for only combinations of indices which are meaningful. For example, the symbol $\forall s, t$ should be interpreted as for all pairs of $s$ and $t$ corresponding to all days $t$ for which ship $s$ is in port.

\section{Formulation}

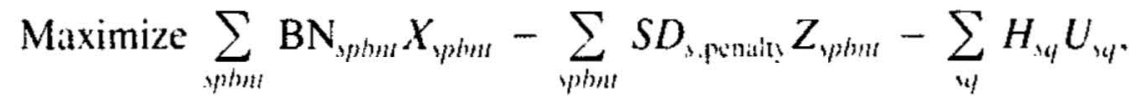

subject to

$$
\begin{aligned}
& \sum_{s h}\left(S D_{\text {, length }}+\mathrm{BTW}\right) X_{\mathrm{v} p l\} t} \leq P D_{p \text {.kngth }}+\mathrm{EXT}, \quad \forall p, t,
\end{aligned}
$$

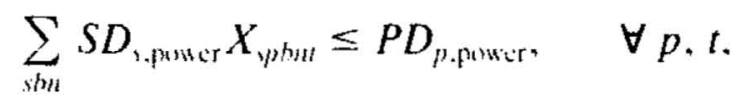

$$
\begin{aligned}
& \sum_{y m}\left(w_{s}+\mathrm{FND}\right) B_{p h} X_{s p h n} \leq W_{k}-\text { TUG, } \quad \forall k, b, t \\
& \sum_{p h m} X_{\text {ypht }}=1, \quad \forall s, t, \\
& \sum_{1} X_{x p h m} \leq 1, \quad \forall p, b, n . t \\
& X_{y p h u t}-X_{\text {yphnt-1) }}-Z_{\text {sphut }} \leq 0, \quad \forall s, p, b, n, t, \\
& \sum_{n \in\{t(1)} \sum_{m} X_{c r p l m}+(n-1) X_{s p h m} \leq(n-1), \quad \forall s, p, b, t, \text { and } n \geq 2 \\
& \sum_{m} \sum_{i r t s} X_{r p p h m}+N X_{s p b \mid t} \leq N, \quad \forall p, b, t, \text { and } s \in \text { NONEST. } \\
& \sum_{m \in i_{(S)}} \sum_{m \cdot n} X_{v p h m t}+(N-n) X_{v p h t} \leq(N-n), \\
& \forall s \in \text { NOOUT, } p, b, t \text { and } n \leq(N \cdots 1) \text {, } \\
& \sum_{s} X_{s p h m}-\sum_{s} X_{p h n-1)} \leq 0 . \quad \forall p, b, t \text { and } n \geq 2 \text {. } \\
& \sum_{p: \sum q(q)} \sum_{m_{i t}} X_{s p h m}+U_{s i} \geq 1, \quad \forall s . q
\end{aligned}
$$




$$
\begin{gathered}
X_{s p h m} \in\{0,1\}, \quad \forall s, p, b, n, t, \\
Z_{s p b u t} \in[0,1], \quad \forall s, p, b, n, t, \\
U_{s q} \in[0,1], \quad \forall s, q .
\end{gathered}
$$

In the above formulation, the objective function is to maximize the ship-to-berth assignment henefits less a berth shift and unperformed service penalties. This penalty decreases the total benefit of the plan each time a vessel is required to move to a different berth or nesting position from day to day in order to receive required services at a new berth or to free its current berth for another ship. Since the formulation encompasses the entire planning horizon, the optimal plan takes into account the arrival on any day of new ships and their required services. Initial ship positions are treated as arrivals on day 0 .

Constraints (6) limit the total length of ships berthed pier side at pier $p$ to be less than the length of the pier plus allowable extension. Constraints (7) ensure that each pier has sufficient power cables to support ships berthed alongside. Constraints (8) provide room for a tug to maneuver among ships berthed in each basin. Constraints (9) ensure each ship is uniquely berthed when scheduled to be in port while constraints (10) allow at most one ship per berthing position. Constraints (11) calculate berth shifting. To illustrate, consider shifting ship FFG5 which is berthed at pier IIN, berth 2 , nesting position 3 on day 5 to pier $10 \mathrm{~N}$, berth 1 , nesting position 1 on day 6 . The constraints (11) yield the following equations of interest.

$$
\begin{aligned}
& X_{\mathrm{FFGS}, 11 \mathrm{~N} .2 .3 .6}-X_{\mathrm{FFG} 5.11 \mathrm{~N} .2 .3 .5} \leq Z_{\mathrm{FFG5.11N.2.3.6},} \\
& X_{\mathrm{FFG} \text { (.5.10N.1.1.6 }}-X_{\mathrm{FFG5.111N.1.1.5}} \leq Z_{\mathrm{FFG5.111N.1.1.6} .}
\end{aligned}
$$

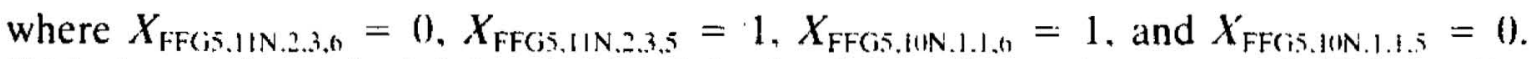
With these values, the left-hand side of the first inequality evaluates to -1 . This implies that $Z_{\mathrm{FF}(5.5 .11 \mathrm{~N} .3 .}$ equals zero at optimality since its objective function coefficient is positive. Similarly, the left-hand side of the second inequality evaluates to 1 which in turn forces $Z_{\mathrm{FF} \text { (5.IIN I, I, n }}$ to be $\mathrm{l}$ to account for shifting FFG5 to a new berth on day 6 . Constraints (12) ensure that shorter ships are berthed outside longer ships while constraints (13) make sure that ships which cannot be nested are berthed by themselves. Constraints (14) guarantee that no ship is berthed outboard from ships which request it. Constraints (15) ensure that berthing positions are filled sequentially. Finally, constraints (16) determine which services are unfultilled. When service $q$ for ship $s$ cannot be fulfilled, the first term in (16) sums to zero which requires $U_{x}$ to be 1 to satisfy the inequality. When considered in conjunction with the last term in the objective function. these constraints insure problem feasibility when it is impossible to fulfill all requested services.

\section{SHIP BERTHING EXAMPLE}

A prototypic model has been evaluated using a GAMS generator [3] and initially solved with XS [1]. The model has been tested using an example with 17 ships, eight piers (see Fig. 1), and a 6-day planning horizon. 
Table 1. Ship characteristics.

\begin{tabular}{|c|c|c|c|c|c|c|c|c|c|c|}
\hline Ship & Length & Draft & $\begin{array}{l}\text { Power } \\
\text { cables }\end{array}$ & Arrive & Depart & Beam & Inspect & Deploy & $\begin{array}{c}\text { No } \\
\text { nesting }\end{array}$ & $\begin{array}{l}\text { Shifting } \\
\text { penalty }\end{array}$ \\
\hline AFS? & 581 & 24 & 4 & 5 & 5 & 79 & & & & 400 \\
\hline AORt & 659 & 33.3 & 3 & 3 & 5 & 96 & & & & 500 \\
\hline DDG4 & 4.37 & 20 & 3 & 2 & 5 & +7 & & & & 300 \\
\hline DDG6 & 437 & 20) & 3 & 1 & 5 & 47 & & & & 300 \\
\hline LHAt & 840 & 26 & 14 & 2 & 5 & 1116 & & & 1 & 400 \\
\hline BB6I & 887 & $3 s$ & 6 & 1 & 2 & 108 & & & & 500 \\
\hline $\mathrm{BBola}$ & 887 & 38 & 6 & 5 & 5 & 108 & & & & 5100 \\
\hline CVN71 & 1.300 & 37 & 8 & 1 & 5 & 134 & & & 1 & $100 \%$ \\
\hline $\mathrm{CV}_{67}$ & 1.300 & 35.9 & 24 & 1 & 5 & 130 & & 200 & 1 & 1000 \\
\hline CV66 & 13000 & 37 & 24 & 1 & 3 & 130 & & $2(x)$ & 1 & 10000 \\
\hline $\mathrm{CG}_{27} 7$ & 547 & 28.8 & $t$ & 1 & 4 & 54.8 & & & & 350 \\
\hline CG31) & 547 & 28.8 & + & 2 & 5 & 54.8 & & & & 350 \\
\hline CG34 & 547 & 28.8 & $t$ & 4 & 5 & 54.8 & & & & 350 \\
\hline $\mathrm{CG}+8$ & 567 & 33 & 6 & 1 & 3 & 55 & 100 & & & 350 \\
\hline$C G .51$ & 566 & 31 & 6 & 1 & 2 & 55 & & & & 350 \\
\hline FFG5 & 414 & 24.2 & 2 & 1 & + & $4+2$ & & 100 & & 300 \\
\hline TAF8 & 524 & 22 & 2 & 1 & 2 & 72 & & & & 400 \\
\hline TAO1S9 & 678 & 34.5 & 4 & 2 & $t$ & 97.5 & & & & 400 \\
\hline
\end{tabular}

This example incorporates a wide variety of ship types: carrier, frigate, destroyer. cruiser, oiler, and battleship. The physical characteristics of each ship include length, draft, number of shore power cables required, arrival date, departure date, beam, and whether the ship can nest. Inspection and deployment factors are identified along with the penalty incurred if a berth shift is required. Table 1 displays a sample of data input for the 17-ship example problem.

To identify any particular ship or ship type, refer to Jane's Fighting Ships, 1988. BB61 a indicates a second inport period for BB61 during the planning horizon. Each pier is characterized in Table 2 by its length, depth and shore power available. The services available pierside include diesel fuel (DFM), JP5 fuel. Military Sealift Command (MSC). Stores, 14OT crane, DESRON2 (DRON2) and COMDESTRUB (CD68) sponsorship. and ordnance handling certification. Table 3 shows the pier and service availability used in the sample problem. The weighted values assigned to each ship for requested services are seen in Table 4.

Table 2. Pier attributes.

\begin{tabular}{lccc}
\hline Pier & Length & Depth & Power cables \\
\hline $12 \mathrm{~N}$ & $1300)$ & 50 & 24 \\
$12 \mathrm{~S}$ & 1300 & 50 & 24 \\
$11 \mathrm{~N}$ & 1397 & 50 & 24 \\
$11 \mathrm{~S}$ & 1397 & 50 & 24 \\
$10 \mathrm{~N}$ & 1300 & 38 & 56 \\
$7 \mathrm{~N}$ & 1350 & 45 & 24 \\
$7 \mathrm{~S}$ & 1350 & 45 & 21 \\
$4 \mathrm{~S}$ & 1347 & 40 & 24 \\
\hline
\end{tabular}


Table 3. Pier/service availability.

\begin{tabular}{lcccccccccc}
\hline Pier & DFM & JP5 & MSC & STR & 140T & 4160V & DRON2 & ORDN & CD68 & TEND \\
\hline $12 \mathrm{~N}$ & 1 & 1 & & & & 1 & & 1 & & \\
$12 \mathrm{~S}$ & 1 & 1 & & & & 1 & & 1 & \\
$11 \mathrm{~N}$ & & & & & & 1 & & 1 & & \\
$11 \mathrm{~S}$ & & & & & & 1 & & 1 & 1 & \\
$10 \mathrm{~N}$ & & & & & & & & 1 & & 1 \\
$7 \mathrm{~N}$ & 1 & 1 & & & & & & 1 & & \\
$7 \mathrm{~S}$ & 1 & 1 & 1 & 1 & 1 & & & & & \\
$4 \mathrm{~S}$ & 1 & 1 & 1 & 1 & & & \\
\hline
\end{tabular}

The remaining physical characteristics for all ships. piers. and basins essential to the problem are given in the complete GAMS model shown in [14] and also available from GAMS Development Corporation. The resulting integer program generated by GAMS has been solved using XS. Figure 3 illustrates the resulting berthing plan. A narrative script follows:

Day 1: Both FFG5 and CG27 are required to berth shift in order to make room for the arrivil and berthing of $\mathrm{CV} 67$. The erosses outboard CG27 indicate that ship's request firr none to berth outboard.

Day 2: TAOI89. LHAt. DDG4. and CG3() arrive inport. CG51 herth shifts to allow (G33) to) herth pierside in accordance with the scheduler's input.

Day 3: BB6I. CG51. and TAFX depart and are underwily on Day 3 whereas AORt arrives in port.

Day t: CG48 and CV6h are underway. CG34 arrives at the base and assumes the herth vacated by $\mathrm{CG} 48$.

Day 5: On Day 5 AFS2 arrives inport and BB61 returns (as BB6la) but to a different berth. TAO189. FFG5. and CG27 are underway for sea.

Table 4. LOGREQ properties for ship services.

\begin{tabular}{|c|c|c|c|c|c|c|c|c|c|c|}
\hline Ship & DFM & JP5 & MSC & STR & $140 \mathrm{~T}$ & $4160 \mathrm{~V}$ & DRON2 & ORDN & CD68 & TEND \\
\hline AFS2 & & & & 600 & $60(0)$ & & & & & \\
\hline AOR4 & 750 & 750 & & & & & & & & \\
\hline LHA4 & & & & & & & & & & \\
\hline DDG4 & & & & & & & & & & \\
\hline DDGis & & & & & & & & & & \\
\hline $\mathrm{BBhl}$ & & & & & & & & & & \\
\hline BB6la & $6(1) 0$ & & & & & & & & & \\
\hline CVN71 & & 900 & & & & 999 & & & & \\
\hline $\mathrm{CV}_{67}$ & & 900 & & & & & & & & \\
\hline CVos & & $y(0)$ & & & & & & & & \\
\hline $\mathrm{CG}_{2} 7$ & & & & & & & & & $f(10)$ & \\
\hline CG30 & & & & & & & & & $4(1) 1$ & \\
\hline CG34 & & & & & & & & & $4(0)$ & \\
\hline CG48 & & & & & & & & & $+(0)$ & \\
\hline$C \mathrm{C} .51$ & & & & & & & & & 400 & \\
\hline FFG.5 & 200 & & & & & & & & & \\
\hline TAFY & & & 700 & $7(x)$ & $f(x)$ & & & & & \\
\hline TAOlSY & & & 700 & & & & & & & \\
\hline
\end{tabular}



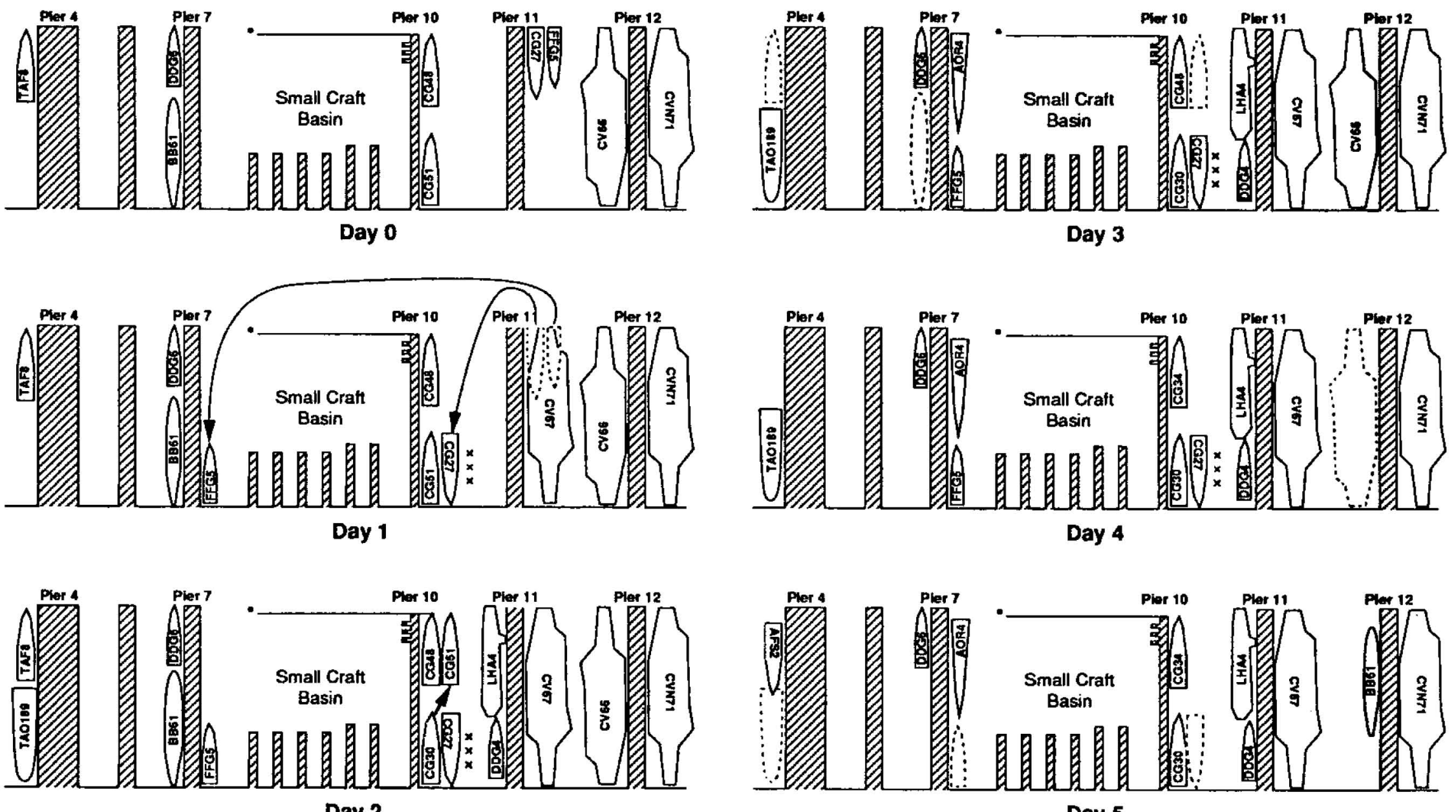

Figure 3. An optimal berthing plan. Shaded ship silhouettes are new berthings. dashed outlines show newly vacated berths, and arrows show berth shifts. 


\section{COMPUTATIONAL EXPERIENCE}

GAMS, the General Algebraic Modeling System [2]. "is designed to make the construction and solution of large and complex mathematical programming models more straightforward for programmers and more comprehensible to users of models". GAMS has been developed to [3]:

- Provide a high-level language for the compact representation of large and complex models.

- Allow changes to be made in model specifications simply and siffely.

- Allow unambiguous statements of algebraic relationships.

- Permit model descriptions that are independent of solution algorithms.

GAMS enabled experimentation and easy changes to both the prototypic ship berthing model and its supporting data. The dollar operator feature in GAMS "provides powerful and concise exception-handling capability." Explicit if-then-else statements constructed within an equation or assignment makes a program more manageable by decreasing the number of equations and variables generated [3]. To illustrate, the compatibility data $C_{\text {sphnt }}$ is represented as a PARAMETER C(S, P, B, N, T) and constraints (7) become the following EQUATION.

POWER(P. T) . .

$\operatorname{SUM}\left((S, B, N) \$ C(S, P, B, N, T), X(S, P, B, N, T)^{*} S D(S, \cdot P W R ')\right)=L=P D(P, \cdot P W R '):$

Here, the dollar operator controls the indices of the summation and GAMS only sums over those indices for which $C(S, P, B, N, T)$ is nonzero, thereby generating only those variables necessary for the model.

The example problem has 1747 constraints, 4522 continuous variables, 942 binary variables, and 25.904 nonzero coefficients. Using Amdahl 5990-500 mainframe, GAMS generates this model in 6 seconds. The default X-system [5] solves the LP relaxation of the example in 2 seconds and renders an optimal integer solution in another second.

Our goal is to demonstrate that the port scheduling model can also be solved quickly and reliably at realistic scale on a modest personal computer (e.g. [1]). A 486/50-MHz personal computer with MS-DOS 5.0 operating system and SVS $C^{3}$ FORTRAN |13| generates the example problem in 17 seconds, solves the LP relaxation in 13 seconds and finally renders an integer solution within $0.9 \%$ of optimality in another 22 seconds. We expect to be able to improve this performance significantly by tuning. This is important because the full-scale Norfolk berth scheduling problem will require some advanced optimization techniques. To illustrate, a problem with 24 piers, 144 berths, and $7+$ ships in port an average of five days over a 7 -day berthing plan contains up to 120,117 constraints and 53,280 binary variables.

Although GAMS is a powerful tool. it can be expensive in terms of computer resources to use routinely and repeatedly. Recall that the example model requires 6 seconds on the Amdahl and 17 seconds on the PC just to generate the input for an optimizer. After solution, simple report writing takes 3 and 6 seconds on the mainframe and PC. respectively. By contrast. models of equivalent size and complexity are generated in a second or less on the mainframe by use of customized problem generators written in general-purpose compiled languages (e.g., FORTRAN). Such old-fashioned generators and report writers take longer to write and debug than GAMS and are harder to modify. but they generate with enormously improved efficiency. 


\section{CONCLUSIONS}

Optimization-based berth scheduling is feasible and effective. The prototype introduced and developed here gives compelling evidence that a computer-based model can express the berthing problem concisely and automatically produces berthing plans capturing an enormous amount of the realism and detail that make such scheduling a challenging manual chore. Better yet, the method developed here encourages human interaction.

In the context of the proposed model. extensive user-friendly facilities can be accommodated to allow a port operations scheduler to manually assign a ship to a specific berth. subset of piers/berths or nesting position. The optimization model then completes the tedious details of the berth plan. Thus, the port operations scheduler can naturally express any "human judgement" issues and the optimization assures that high-quality berth plans are easily and quickly produced.

This optimization program would also give the scheduler the flexibility to evaluate atternate "what if" berthing plans. In this role, quick-response identification of upcoming infeasibilities may be as useful as comparative evaluations of the relative merit of alternate plans. There is no current manual analog for this capability, nor is it likely that the manual time and effort will be available to devote to much more than cursory analysis of schedule changes.

Independent of the research reported here. NARDAC [10] has designed a computerbased data management system, called BASIS (Bases and Stations Information System) which has a Port Services module. The decision support model we propose is ideally suited for integration into such a system.

Port scheduling is crucial to the U.S. Navy. Considering the tempo of schedule changes and the meticulous detail which preparation of every schedule must consider, a manual scheduler is hard-pressed to weigh myriad alternatives and fine-tune every alteration. It is inevitable that oversights will lead to delays. If an automatic, optimization-based decision support system prevents unnecessary delays or berth shifts, then such a svstem clearly contributes to the readiness of the fleet.

\section{APPENDIX A. NAVAL STATION NORFOLK BERTH SCHEDULING GUIDELINES}

1. Due to pier superstructure. the following ship types cannot berth at these prohibited locations:

\begin{tabular}{ll} 
Ship type & Prohibited locations \\
\hline LSD. LPD & Pier 4 herths 5 and 6 \\
CV CVN & Pier 2.3.4. 10
\end{tabular}

2. The fendering system linits the ship types certain piers are or can be configured for. All other ship types may go to any berth provided it is physically feasible and shore power is available.

\begin{tabular}{ll} 
Ship type & \multicolumn{1}{c}{ Compatible piers } \\
\hline BB & all except I0 \\
LHA & $5.7 .10 .11 .12 .25 \mathrm{~N}$ \\
LPH & 2.5 .7 .11 .12 \\
LPD & $2.3 .4 .5,7.10-5,11.12$ \\
CV iCVN & $7 \mathrm{~N} .11 .12$
\end{tabular}


3. Ships would like to be berthed at piers that their respective squadrons sponsor.

\begin{tabular}{ll} 
Pier & Sponsor squadron \\
\hline 20 & SERVGRU 4 \\
21 & DESRON 2 \\
24.25 & DESRON 10 \\
11.25 & CRUDESGRU: 8
\end{tabular}

4. During high port loading. ships berthed bow out may extend up to 28) feet beyond the end of the pier.

5. Maintain a distance of 50 feet between ships berthed how-to-bow. bow-to-stern. stern-tobow, and $25-50$ feet between a ship's how-to-stern and a seawall.

6. The larger the ship. the higher its priority should be in receiving services.

7. Do not nest CV, CVN, LHA, LPH, and LPDs due to their hull structure.

8. An outboard ship's length must be less than or equal to the inboard ship's length. This minimizes the stress on mooring lines. However. during high port loading, the outhoard ship maly be up to 20 feet longer.

9. Preferably, berth ships in "LPREEP" near a tender or Ship Intermediate Maintenance Facility (SIMA), responsible for repairs.

10. Certain services are rendered unly at specific piers: e.g. . refueling pier side. ordnance transfer, major stores loading. collimation (piers 5, 7. 24, 25: herths 1 and 2). sonar testing (bow out. end of pier), and cranes.

11. The maximum number of ships nested is usually two but mav be as many as four. This is primarily due to shore power limitations.

12. If LHAs require lowering their ramp. they must do so on piers 5. 7. 11, or 12. (The driveon and -off ramp is used to load vehicles.)

13. Certain ships must go to specific berths (e.g. USS Mount Whitney. Pier 25-1).

14. Ships preparing for deployment and inspections have a higher priority for services than others of the same ship type.

15. Two ships of certain classes, Spruance, Oiler. BB. Ticonderoga, Yorktown, DDG. FF, may berth Chinese (bow-to-stern). This is not a major factor but may be a consideration. (This is an infrequent event.)

16. Ships undergoing a Radiation Hazard (RADHAZ) survey must be 20() feet out of range of any line-of-sight shore structure or other ship's superstructure. (This is an infrequent event.)

17. Berth ships (AOE. AO, AOR, AFS) requesting inport underway stream qualification training tests, and underway replenishment standard qualitication trials (UNREP SOTS) across from each other in the same basin or across an unobstructed pier. (This is an infrequent event.) See Figure 4.

18. SUBRON 6 and 8 are responsible for assigning submarines and tenders $t o$ berths on piers 22 and 23. Thus, piers 22 and 23 are removed from our consideration.

19. Phone lines; fresh water; $125 \mathrm{psi}$ steam; and collection, holding, and transfer (CHT) hookups are not scarce at the Norfolk Base and are therefore not considered in the model.

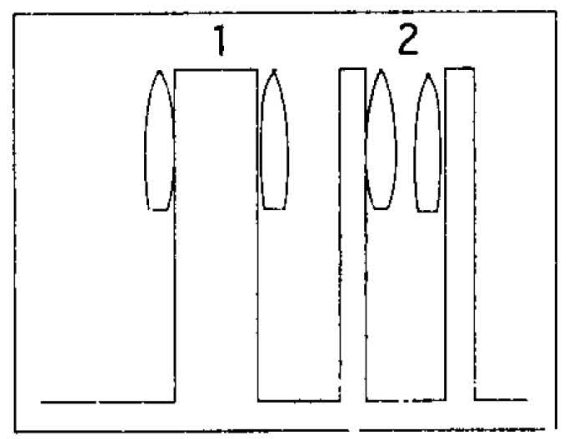

Figure 4. UNREP SQTTS berthing positions. 


\section{REFERENCES}

[1] Bausch. D., and Brown, G.. "A PC Environment for Large-scale Programming," OR/MS Today, 15(3), (1988).

[2] Bisschop. J.. and Meeraus, A.. "On the Development of a General Algebraic Modeling System in a Strategic Planning Environment." Mathematical Programming Studies, 20 (1982).

[3] Brooke. A.. Kendrick. D., and Meeraus. A.. G.4.MS: A Users Guide. Scientific Press. 1988.

14] Brown. G., and Graves. G.. "Design and Implementation of a Large-scale (Mixed-Integer) Optimization System," ORSA'TIMS. Las Vegas. Nevada. November 1975.

[5] Brown. G., and Olson, M., "Dynamic Factorization in Large-Scale Optimization," Mathematical Programming (to be published).

[6] COMNAVSTANORVA. Naval Station Norfolk. Virginia Letter 3126:Serial 1),3/2456 to Superintendent. Naval Postgraduate School. Monterey. California, Subject: Operations Analvsis Study of Berthing at Naval Station Piers: Request for, 10 November 1987.

[7] COMNAVSURFLANT. Naval Surface Force, U.S. Atlantic Fleet Letter 3120:Serial N321 4391 to Commanding Officer, Naval Station, Norfolk. Virginia, Subject: Port Loading. 9 April 1987.

18] Defense Mapping Agency. Fleet Guide, Hampton Roads (13th ed.). Publication 9.4) Chapter 5. Hydrographic/Topographic Center, 1986.

[9] Jthe's Fighting Ships 1988-199. Jane's Yearbooks. London, 1988.

[10] NARDAC, Naval Regional Data Automation Center San Diego. Document No. UDX146I FD-(0). Bases and Stations Information Systems (BASIS). Functional Description for Port Services Draft. January 1988.

[11] Navy. Department of. NWP-7 (Rev. A), Operational Reports. November 1981.

[12] Papworth. B.. Prospective Commanding Officer Briefing Dratt, Naval Station Norfolk, VA, June l9ss.

[13] Silicon Valley Sottware. Inc., SVS C FORTRAN 77 IM. San Mateo, CA 1992.

[14] Thurman, K.P.. "Optimal Ship Berthing Plans," Masters Thesis, Naval Postgraduate School. Monterey, CA, March 1989.

[15] Wing. V.F., SURFSKED an Optimization Aid for Surfuce Combutant Interdeplovment Schedilling. Masters thesis. Naval Postgraduate School, Monterey, CA. September 1986.

Manuscript received August 12. 1992

Revised manuscript received March 22. 1993

Accepted July 15, 1993 